\title{
A thermodynamic approach towards glass-forming ability of amorphous metallic alloys
}

\author{
SONAL R PRAJAPATI, SUPRIYA KASYAP and ARUN PRATAP* \\ Condensed Matter Physics Laboratory, Applied Physics Department, Faculty of Technology and Engineering, \\ The M. S. University of Baroda, Vadodara 390001, India
}

MS received 31 May 2014; accepted 7 August 2015

\begin{abstract}
A quantitative measure of the stability of a glass as compared to its corresponding crystalline state can be obtained by calculating the thermodynamic parameters, such as the Gibbs free energy difference $(\Delta G)$, entropy difference $(\Delta S)$ and the enthalpy difference $(\Delta H)$ between the super-cooled liquid and the corresponding crystalline phase. $\Delta G$ is known as the driving force of crystallization. The driving force of crystallization $(\Delta G)$ provides very important information about the glass-forming ability (GFA) of metallic glasses (MGs). Lesser the driving force of crystallization more is the GFA. The $\Delta G$ varies linearly with the critical size $\left(d_{c}\right)$. According to Battezzati and Garonne the parameter $\gamma\left(=\left(1-\left(\Delta H_{x} / \Delta H_{\mathrm{m}}\right)\right) /\left(1-\left(T_{x} / T_{\mathrm{m}}\right)\right)\right)$ in the expression for $\Delta G$ should be a constant (i.e., 0.8), but its uniqueness is not observed for all MGs. The thermal stability of various alloy compositions is studied by their undercooled liquid region $\left(\Delta T=T_{x}-T_{\mathrm{g}}\right)$. Large $\Delta T_{x}$ implies greater stability against crystallization of the amorphous structure. Other GFA parameters are also calculated and correlated with critical size $\left(d_{c}\right)$.
\end{abstract}

Keywords. Metallic glass; Gibbs free energy; critical size.

\section{Introduction}

Metallic alloys can be converted into metallic glasses by cooling their melt at a high rate, i.e., $10^{5}-10^{6} \mathrm{~K} \mathrm{~s}^{-1}$, such that their molecules does not get sufficient time to occupy stable configuration, thereby suppressing their crystallization event. These supercooled metallic alloys with a disordered atomic scale arrangement and connected by metallic bonds are known as 'metallic glasses (MGs)'. Metallic alloys which fail to crystallize during solidification even at low critical cooling rate, i.e., less than $100 \mathrm{~K} \mathrm{~s}^{-1}$, form 'bulk metallic glasses (BMGs)' with thickness ranging from $1 \mathrm{~mm}$ to several centimetres due to smaller cooling rates. MGs and BMGs are prepared by different synthesis routes. Melt spinning technique is used to prepare amorphous ribbons of metallic alloys, which involves rapid cooling. On the other hand, BMGs are formed by different methods such as copper mould casting, arc melting, which require comparatively low cooling rate. These metastable materials possess excellent properties, such as high strength, high hardness, exhibit good corrosion resistance and attractive soft magnetic behaviour. ${ }^{1,2}$ This inspires us to study the thermal properties of MGs in the undercooled region. To design an alloy having excellent glass-forming ability (GFA), many empirical approaches have been proposed based on trial and error experiments, ${ }^{3-5}$ but there are no justified theories and scientific rules. The GFA of alloys may be characterized by the Gibbs free energy

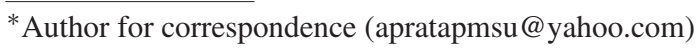

difference $(\Delta G)$. Decreasing $\Delta G$ acts as a driving force for nucleation causing an increase in critical nucleation work and a reduction in nucleation rate. Lele et $a l^{6}$ studied the temperature dependence of free energy of crystallization. It provides an insight for understanding the effect of heating rate on nucleation in undercooled region. The value of $\Delta G$ can be calculated by the measurement of specific heat difference $\Delta C_{\mathrm{p}}$, which is difficult to attain experimentally. So, different theoretical approximations of $\Delta C_{\mathrm{p}}$ results in a variety of expressions of $\Delta G{ }^{7,8}$ To understand glass formation and to predict GFA, Guo et $a l^{9}$ have imposed physically accepted boundary conditions to evaluate the GFA criteria, and performed statistical analysis in order to identify the best GFA criterion. Recently, Tang et $a l^{10}$ have studied the GFA of Ce-based alloys, using different GFA parameters.

All GFA parameters are correlated with in order to interpret its sensitivity towards the GFA of MGs. Senkov ${ }^{11}$ introduced GFA parameter based on fragility of MG and found a good correlation with critical cooling rate. Also Xiu-lin and $\mathrm{Ye}^{12}$ formulated a new GFA parameter based on thermodynamic analysis and found a good correlation with $d_{\mathrm{c}}$ for $\mathrm{Ca}-\mathrm{Mg}-\mathrm{Cu}$ BMGs. In the present work, $\Delta G$ and other GFA parameters ${ }^{5,13-16}$ for different MGs are calculated and are correlated with critical size to study the GFA of metallic alloys. $\Delta G$ is evaluated by different theoretical expressions. We have calculated $\Delta G$ to understand the glass formability of various MGs, i.e., $\mathrm{Ca}_{50} \mathrm{Mg}_{25}$ $\mathrm{Cu}_{25},{ }^{17} \mathrm{Mg}_{65} \mathrm{Cu}_{25} \mathrm{Y}_{10},{ }^{18,19} \mathrm{Mg}_{65} \mathrm{Cu}_{20} \mathrm{Zn}_{5} \mathrm{Y}_{10}{ }^{20} \mathrm{Mg}_{59.5} \mathrm{Cu}_{22.9}$ $\mathrm{Ag}_{6.6} \mathrm{Gd}_{11},{ }^{21,22} \mathrm{Fe}_{41} \mathrm{Co}_{7} \mathrm{Cr}_{15} \mathrm{Mo}_{14} \mathrm{C}_{15} \mathrm{~B}_{6} \mathrm{Y}_{2},{ }^{23,24} \mathrm{Zr}_{41.2} \mathrm{Ti}_{13.8}$ $\mathrm{Cu}_{12.5} \mathrm{Ni}_{10} \mathrm{Be}_{22.5},{ }^{24,25} \mathrm{Zr}_{65} \mathrm{Cu}_{17.5} \mathrm{Ni}_{10} \mathrm{Al}_{7.5},{ }^{24,26,27} \mathrm{Pd}_{40} \mathrm{Ni}_{40}$ 
$\mathrm{P}_{20},{ }^{24,26,28} \quad \mathrm{Pd}_{40} \mathrm{Ni}_{10} \mathrm{Cu}_{30} \mathrm{P}_{20},{ }^{24,26,29}$ and $\mathrm{Au}_{76.9} \mathrm{Ge}_{13.65}$ $\mathrm{Si}_{9.45}{ }^{28,30}$ by different expressions.

\section{Theory}

The general equation for $\Delta G$ between the undercooled liquid and corresponding crystalline phase is given by

$$
\begin{aligned}
& \Delta G=\Delta H-T \Delta S \\
& \Delta H=\Delta H_{\mathrm{m}}-\int_{T}^{T_{\mathrm{m}}} \Delta C_{\mathrm{p}} \mathrm{d} T \\
& \text { and } \Delta S=\Delta S_{\mathrm{m}}-\int_{T}^{T_{\mathrm{m}}} \Delta C_{\mathrm{p}} \frac{\mathrm{d} T}{T}
\end{aligned}
$$

Where, $\Delta S_{\mathrm{m}}, \Delta H_{\mathrm{m}}$ and $T_{\mathrm{m}}$ are the entropy, enthalpy and temperature of fusion, respectively. They are related to each other by the relation:

$$
\Delta S_{\mathrm{m}}=\Delta H_{\mathrm{m}} / T_{\mathrm{m}}
$$

So the equation becomes,

$$
\Delta G=\Delta S\left(T_{\mathrm{m}}-T\right)-\int_{T}^{T_{\mathrm{m}}} \Delta C_{\mathrm{p}} \mathrm{d} T+T \int_{T}^{T_{\mathrm{m}}} \Delta C_{\mathrm{p}} \mathrm{d}(\ln T)
$$

Turnbull ${ }^{5}$ assumed $\Delta C_{\mathrm{p}}$ to be zero. So $\Delta G$ can be written as

$$
\Delta G=\Delta H_{\mathrm{m}}\left(\frac{\Delta T}{T_{\mathrm{m}}}\right) .
$$

Assuming $\Delta C_{\mathrm{p}}=$ constant, one gets

$$
\Delta G=\Delta S_{\mathrm{m}}\left(T_{\mathrm{m}}-T\right)+\Delta C_{\mathrm{p}}\left[T \ln \left(\frac{T_{\mathrm{m}}}{T}\right)-\left(T_{\mathrm{m}}-T\right)\right] .
$$

To simplify the above equation, Thompson and Spaepen ${ }^{7}$ (T-S) used the following approximation:

$$
\ln \frac{T_{\mathrm{m}}}{T} \cong \frac{2 \Delta T}{T_{\mathrm{m}}+T}
$$

And they derived an expression given as

$$
\Delta G=\frac{\Delta H_{\mathrm{m}} \Delta T}{T_{\mathrm{m}}}\left(\frac{2 T}{T_{\mathrm{m}}+T}\right) .
$$

This equation is only valid for small $\Delta T$, and leads to error in calculations of $\Delta G$ values at larger undercooling.

Generally, multicomponent MGs exhibit larger undercooling range. Hence, equation (6) cannot be used for a wide range of MGs.

Lad et $a l^{8}$ assumed $\Delta C_{\mathrm{p}}=\Delta H_{\mathrm{m}} / T_{\mathrm{m}}$ and used Taylor series expansion of $\ln \left(T_{\mathrm{m}} / T\right)=\ln (1+\Delta T / T)=\Delta \mathrm{T}[1-$
$\Delta T / 2 T] / T$, retaining terms up to second order and derived the expression:

$$
\Delta G=\frac{\Delta H_{\mathrm{m}} \Delta T}{T_{\mathrm{m}}}\left(1-\frac{\Delta T}{2 T}\right)[\text { Lad-I }]
$$

Again, considering Taylor series expansion of $\ln \left(T_{\mathrm{m}} / T\right)=$ $\ln \left(1+\Delta T /\left(T_{\mathrm{m}}+T\right) / 2\right)$ and retaining up to second-order terms, i.e., $\ln \left(T_{\mathrm{m}} / T\right)=4 T \Delta T /\left(T_{\mathrm{m}}+T\right)^{2}$, Lad et $a l^{31}$ gave the expression:

$$
\Delta G=\frac{\Delta H_{\mathrm{m}} \Delta T}{T_{\mathrm{m}}}\left(\frac{4 T^{2}}{\left(T+T_{\mathrm{m}}\right)^{2}}\right)[\mathrm{Lad}-\mathrm{II}]
$$

As stated by Hoffman ${ }^{32}$

$$
\ln \frac{T_{\mathrm{m}}}{T}=2 \frac{T_{\mathrm{m}}-T}{T_{\mathrm{m}}+T} .
$$

With this approximation equation becomes

$$
\Delta G=\frac{\Delta H_{\mathrm{m}} \Delta T}{T_{\mathrm{m}}}\left(\frac{T}{T_{\mathrm{m}}}\right) .
$$

According to Battezatti and Garone ${ }^{33}$ the expression for $\Delta G$ is given as follows:

$$
\Delta G=\Delta S\left(T_{\mathrm{m}}-T\right)-\gamma \Delta S_{\mathrm{m}}\left[\left(T_{\mathrm{m}}-T\right)-T \ln \left(T_{\mathrm{m}} / T\right)\right] .
$$

The $\gamma$-parameter in the above equation is represented as:

$$
\gamma=\frac{\left(1-\Delta H_{x} / \Delta H_{\mathrm{m}}\right)}{\left(1-\Delta T_{x} / \Delta T_{\mathrm{m}}\right)},
$$

where $\Delta H_{x}$ denotes the enthalpy difference at crystallization.

Singh and $\mathrm{Holz}^{34}$ ( $\mathrm{S}$ and $\mathrm{H}$ ) gave the following expression for linear variation of $\Delta C_{\mathrm{p}}$ with $T$ :

$$
\Delta G=\frac{\Delta H_{\mathrm{m}} \Delta T}{T_{\mathrm{m}}}\left(\frac{7 T}{T_{\mathrm{m}}+6 T}\right) .
$$

$\mathrm{Ji}$ and $\operatorname{Pan}^{35}$ considered hyperbolic variation of $\Delta C_{\mathrm{p}}$ with $T\left(\Delta C_{\mathrm{p}}=\Delta H_{\mathrm{m}} / T\right)$ and derived the following expression:

$$
\Delta G=\frac{2 \Delta H_{\mathrm{m}} \Delta T}{T_{\mathrm{m}}}\left(\frac{T}{T_{\mathrm{m}}+T}-\frac{\Delta T^{2} T_{\mathrm{m}}}{3\left(T_{\mathrm{m}}+T\right)^{3}}\right) .
$$

Dubey and Ramchandrarao ${ }^{36}$ derived expression for $\Delta G$ based on the hole theory of liquids given as:

$$
\Delta G=\frac{\Delta H_{\mathrm{m}} \Delta T}{T_{\mathrm{m}}}-\frac{\Delta C_{\mathrm{p}}^{\mathrm{m}}(\Delta T)^{2}}{2 T}\left(1-\frac{\Delta T}{6 T}\right) .
$$

Finally Lele et $a l^{6}$ derived an expression of $\Delta G$ to study its temperature dependence for the entire undercooled region represented as:

$$
\Delta G=\frac{\Delta H_{\mathrm{m}} \Delta T}{T_{\mathrm{m}}}-\frac{\Delta C_{\mathrm{p}}^{\mathrm{m}}(\Delta T)^{2}}{\left(T_{\mathrm{m}}+T\right)} .
$$




\section{Results and discussion}

\subsection{Regression analysis}

The reliability of GFA criteria is evaluated by linear regression analysis and hence these criteria are correlated to their corresponding $d_{\mathrm{c}}$. The GFA criterion is considered to be better if the coefficient of correlation $R^{2}$ is larger. The GFA parameters are calculated based on the available experimental data of characteristic temperatures, crystallization enthalpy and fusion enthalpy of BMGs in the literature. Critical size is a conclusive criterion for measuring GFA of BMGs. So $d_{\mathrm{c}}$ is related with other parameters to check whether these parameters can be used to evaluate the GFA. A statistical correlation factor, $R^{2}$ have been evaluated from the plots of $d_{\mathrm{c}} v s$. GFA parameter for various BMGs. Higher the value of $R^{2}$, better is the correlation between $d_{\mathrm{c}}$ and GFA parameters. The value of $R^{2}$ can give idea about how efficient are the different GFA parameters to evaluate GFA of MGs. The value of $R^{2}$ determines the relationship between GFA criteria and $d_{\mathrm{c}}$. It should reflect one-to-one correspondence between the two variables. If the value of $R^{2}$ is around unity, it is considered to be highly correlated and having exact linear relationship. The advantage of doing such a regression analysis lies in the fact that it provides consideration to select GFA criteria, and this study is useful to get a quantitative idea about how different GFA parameters reflect the GFA of different metallic alloys.

Figure 1a-d shows the plots of $d_{\mathrm{c}}$ vs. thermodynamic parameter $\Delta G$, and other parameters $T_{\mathrm{rg}}, \Delta T_{x}, Q, \alpha, \beta, \gamma_{\mathrm{m}}$, respectively, for the BMGs listed in table 1. By using the linear regression method, a linear relationship can be obtained between $d_{\mathrm{c}}$ and GFA parameters. From the plots it can be observed that all GFA parameters show a correlation with $d_{\mathrm{c}}$, indicating that all these parameters to a certain range reflect GFA of alloys. The values of correlation coefficient $R^{2}$ were computed to be 0.67 for the $d_{\mathrm{c}}-\Delta G$ plot, $0.01,0.58,0.64$, 0.53 for the $d_{\mathrm{c}}-Q, \gamma_{\mathrm{m}}, \alpha, \beta$ plots, 0.68 for $d_{\mathrm{c}}-T_{\mathrm{rg}}$ plot and 0.32 for $d_{\mathrm{c}}-\Delta T_{x}$ plot, respectively. From the values of $R^{2}$, it can be observed that $\Delta G$, which is the driving force of crystallization and reduced glass transition temperature $T_{\text {rg }}$, better represents GFA of different MGs. $\Delta G\left(T_{\mathrm{g}}\right)$ varies inversely with $d_{\mathrm{c}}$ and hence it shows a negative correlation with $d_{\mathrm{c}}$. As $\Delta G\left(T_{\mathrm{g}}\right)$ increases, $d_{\mathrm{c}}$ decreases and hence GFA decreases.
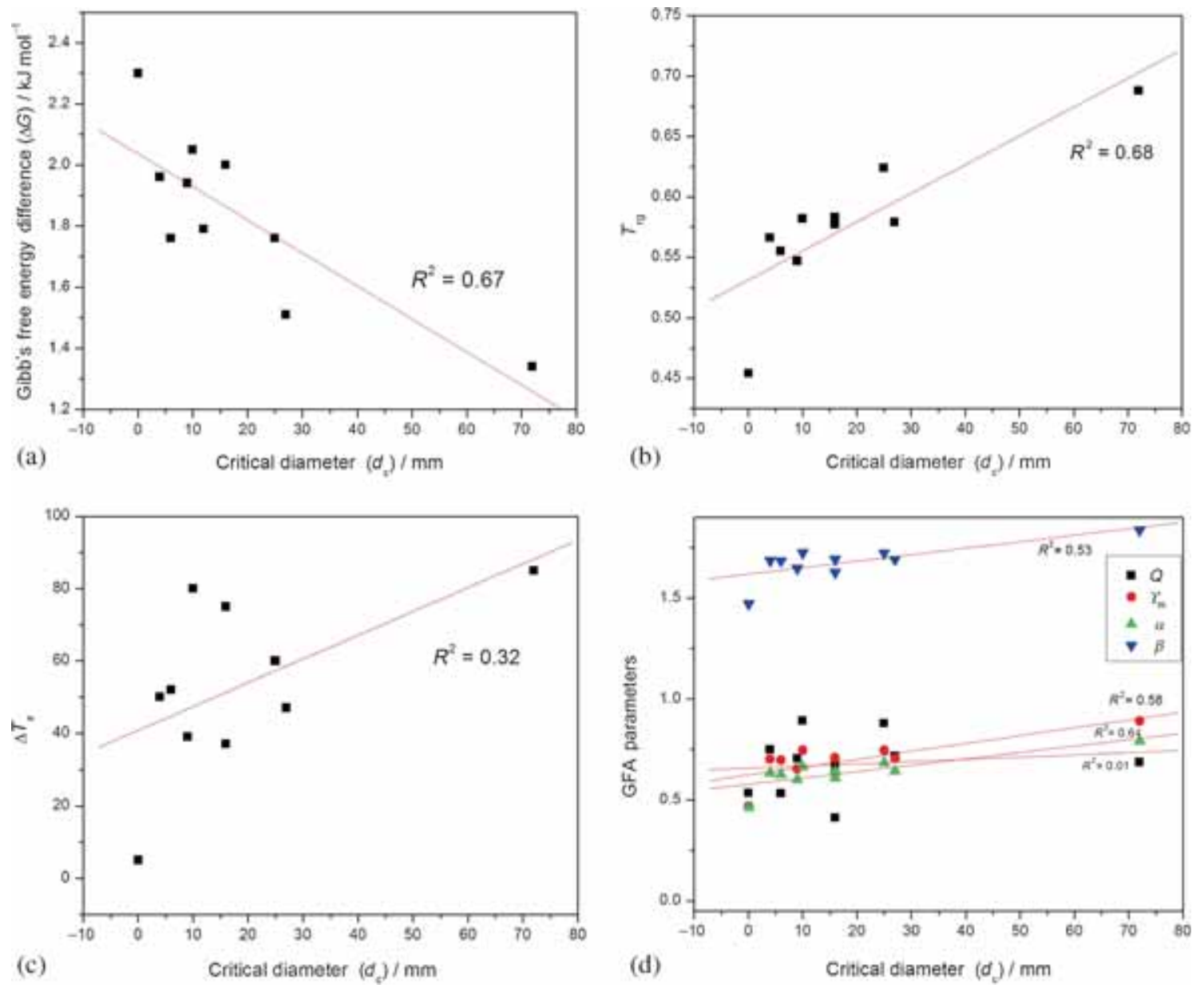

Figure 1. Variation of Gibb's free energy difference $\Delta G, T_{\mathrm{rg}}, \Delta T_{x}$ and other GFA parameters with critical diameter $\left(d_{\mathrm{c}}\right)$. 
Table 1. Thermodynamic parameter $\Delta G$ by different theoretical expressions.

\begin{tabular}{|c|c|c|c|c|c|c|c|c|c|c|}
\hline \multirow[b]{2}{*}{ Systems } & \multirow[b]{2}{*}{$d_{\mathrm{c}}(\mathrm{mm})$} & \multicolumn{9}{|c|}{$\Delta G\left(T_{\mathrm{g}}\right)$ by different expressions $\left(\mathrm{kJ} \mathrm{mol}^{-1}\right)$} \\
\hline & & Lad-I & Lad-II & Hoffman & Turnbull & Ji and Pan & $\mathrm{S}$ and $\mathrm{H}$ & $\mathrm{T}$ and $\mathrm{S}$ & $B$ and $\mathrm{G}$ & $\begin{array}{c}\gamma \\
\text { (equation 11) }\end{array}$ \\
\hline $\mathrm{Ca}_{50} \mathrm{Mg}_{25} \mathrm{Cu}_{25}$ & 9 & 2.287 & 1.938 & 2.037 & 3.193 & 2.424 & 2.954 & 2.487 & 2.339 & 1.29 \\
\hline $\mathrm{Mg}_{65} \mathrm{Cu}_{25} \mathrm{Y}_{10}$ & 4 & 2.317 & 1.961 & 2.117 & 3.697 & 2.576 & 3.341 & 2.692 & 2.718 & 1.05 \\
\hline $\mathrm{Mg}_{65} \mathrm{Cu}_{20} \mathrm{Zn}_{5} \mathrm{Y}_{10}$ & 6 & 2.082 & 1.760 & 1.898 & 3.289 & 2.308 & 2.984 & 2.410 & 2.000 & 1.57 \\
\hline $\mathrm{Mg}_{59.5} \mathrm{Cu}_{22.9} \mathrm{Ag}_{6.6} \mathrm{Gd}_{11}$ & 27 & 1.791 & 1.515 & 1.599 & 2.555 & 1.912 & 2.354 & 1.967 & 1.805 & 1.35 \\
\hline $\mathrm{Fe}_{41} \mathrm{Co}_{7} \mathrm{Cr}_{15} \mathrm{Mo}_{14} \mathrm{C}_{15} \mathrm{~B}_{6} \mathrm{Y}_{2}$ & 16 & 2.375 & 2.004 & 2.134 & 3.535 & 2.572 & 3.232 & 2.661 & 2.087 & 1.78 \\
\hline $\mathrm{Zr}_{41.2} \mathrm{Ti}_{13.8} \mathrm{Cu}_{12.5} \mathrm{Ni}_{10} \mathrm{Be}_{22.5}$ & 25 & 2.065 & 1.760 & 1.836 & 2.774 & 2.163 & 2.585 & 2.209 & 2.134 & 1.2 \\
\hline $\mathrm{Zr}_{65} \mathrm{Cu}_{17.5} \mathrm{Ni}_{10} \mathrm{Al}_{7.5}$ & 16 & 2.754 & 2.324 & 2.487 & 4.198 & 3.008 & 3.822 & 3.124 & 2.880 & 1.31 \\
\hline $\mathrm{Pd}_{40} \mathrm{Ni}_{40} \mathrm{P}_{20}$ & 10 & 2.417 & 2.050 & 2.151 & 3.335 & 2.552 & 3.092 & 2.615 & 2.604 & 1.08 \\
\hline $\mathrm{Pd}_{40} \mathrm{Ni}_{10} \mathrm{Cu}_{30} \mathrm{P}_{20}$ & 72 & 1.536 & 1.337 & 1.373 & 1.905 & 1.576 & 1.805 & 1.596 & 0.994 & 3.09 \\
\hline $\mathrm{Au}_{76.9} \mathrm{Ge}_{13.65} \mathrm{Si}_{9.45}$ & 0.04 & 2.466 & 2.302 & 2.642 & 5.597 & 3.263 & 4.826 & 3.589 & 4.124 & 0.8 \\
\hline
\end{tabular}

Lower the value of $\Delta G$, lesser will be the driving force of nucleation, which degrades the crystallization hence better will be the GFA. So thermodynamically the GFA of metallic alloys can be understood by $\Delta G\left(T_{\mathrm{g}}\right)$. Other GFA parameters show a reasonable linear relation with $d_{\mathrm{c}}$, except for $T_{\mathrm{rg}}$. As $T_{\mathrm{rg}}$ increases GFA also increases and it shows a positive correlation with $d_{\mathrm{c}}$. GFA of MG is considered to be high if the value of $T_{\mathrm{rg}}$ lies in the range 0.66-0.69. In the present case $\mathrm{Pd}_{40} \mathrm{Ni}_{10} \mathrm{Cu}_{30} \mathrm{P}_{20}$ has $T_{\text {rg }}$ value of 0.68 , indicating that it is a best glass former among all. The parameter $\alpha$ derived by Mondal and Murty ${ }^{37}$ is independent of $T_{\mathrm{g}}$, so for metallic alloys for which distinct $T_{\mathrm{g}}$ is not observed the GFA can be estimated which proves its applicability. The parameter $Q$ is derived based on consideration of liquid-phase stability, resistance to crystallization and enthalpy of crystallization, which is heating rate dependent. So it may not be sufficient to study the GFA of metallic alloys. $\Delta T_{x}$ represents the stability of glass, i.e., how far is the crystallization from glass transition. A greater value of $\Delta T_{x}$ represents greater stability of glass against crystallization. But from figure $1 \mathrm{c}$ it can be seen that there exists a weak correlation between $\Delta T_{x}$ and $d_{\mathrm{c}}$, which implies that GFA is not closely related to $\Delta T_{x} . d_{\mathrm{c}}$ represents GFA of MGs, as $d_{\mathrm{c}}$ increases GFA increases. A good GFA parameter is expected to show one-to-one correspondence with $d_{\mathrm{c}}$. So for the same value of $d_{\mathrm{c}}$ a good GFA parameter should have same values. But for the parameter $\Delta T_{x}$ few MGs with same value of $d_{\mathrm{c}}$ have different $\Delta T_{x}$ values. Although GFA and glass thermal stability are related properties, $\Delta T_{x}$ cannot be used to understand both of them. Weinberg ${ }^{38}$ found that a high GFA does not always indicate a high thermal stability. Hence, GFA and thermal stability can be different for few MGs. Therefore $\Delta T_{x}$ cannot be used as a GFA parameter.

In the present case, correlation between GFA criteria and $d_{\text {c }}$ gives lower value of $R^{2}$. This may be due to the fact that the compositions of metallic alloys used in this study are significantly different from each other. The MGs having slight variation in composition show high value of $R^{2}$. Cai $e t$ $a l^{39}$ studied GFA of Zr-Al-Ni-Cu-based bulk MGs and found that GFA parameters show strong correlation with critical size.

From figure 1 it can be observed that different GFA parameters deviate from the fitted line. For some GFA criteria, the deviation from the fitted line is quite large as the regression analysis is based on dispersed data on different metallic systems.

The values of $R^{2}$ for $\alpha$ and $\beta$ are found to be higher than that of $\Delta T_{x}$, which imply that they are strongly correlated and better indicator of GFA. The weak correlation of $\Delta T_{x}$ is due to the fact that it can only reflect the stability of glass, whereas $\alpha$ and $\beta$ combine both the properties i.e., thermal stability of glass and ease of glass formation. It is reported in literature that some glass-forming criteria such as $\Delta T_{x}$ and $T_{\mathrm{rg}}$ when correlated with $R_{\mathrm{c}}$ or $d_{\mathrm{c}}$ show a high degree of diversion in number of cases. ${ }^{40,41}$ So analysing data which is highly distributed may not provide accurate results. The value of $R^{2}$ for the plots of different GFA parameter with $d_{\mathrm{c}}$ is not so high because $d_{\mathrm{c}}$ is also dependent on different casting conditions used by different researchers.

\subsection{Estimation of Gibbs free energy difference}

$\Delta G$ plays an important role in predicting GFA of metallic alloys. Driving force for crystal nucleation can be estimated by the calculation of a thermodynamic parameter, i.e., $\Delta G$. The value of $\Delta G$ increases with lowering of temperature due to decrease in entropy of metallic alloy. It indicates that at lower temperature ample amount of driving force is available for crystallization. Hence, nucleation starts at lower temperature followed by the growth of crystal. As temperature increases growth of stable nuclei takes place. At glass transition temperature $\left(T_{\mathrm{g}}\right)$ the driving force is maximum, which allows the amorphous alloy to move towards crystallization. With further increase in temperature, $\Delta G$ approaches towards zero. Hence, crystallization event ends due to increase in entropy of the alloy resulting in melting of alloy. So estimation of $\Delta G$ at $T_{\mathrm{g}}$ becomes important to study the GFA of metallic alloys. 
Table 2. Thermodynamic parameter $\Delta G$ for different metallic glasses.

\begin{tabular}{lccc}
\hline & & \multicolumn{2}{c}{$\Delta G\left(T_{\mathrm{g}}\right)$ by different expressions $\left(\mathrm{kJ} \mathrm{mol}^{-1}\right)$} \\
\cline { 3 - 4 } Systems & $\begin{array}{c}\Delta G\left(T_{\mathrm{g}}\right)\left(\mathrm{kJ} \mathrm{mol}^{-1}\right) \\
\text { Experimental }\end{array}$ & $\begin{array}{c}\text { Dubey and } \\
\text { Ramchandrarao }\end{array}$ & Lele et al \\
\hline $\mathrm{Mg}_{65} \mathrm{Cu}_{25} \mathrm{Y}_{10}$ & 2.761 & 2.601 & 2.787 \\
$\mathrm{Zr}_{41.2} \mathrm{Ti}_{13.8} \mathrm{Cu}_{12.5} \mathrm{Ni}_{10} \mathrm{Be}_{22.5}$ & 2.190 & 2.361 & 2.414 \\
$\mathrm{Pd}_{40} \mathrm{Ni}_{40} \mathrm{P}_{20}$ & 2.953 & 2.573 & 2.677 \\
$\mathrm{Pd}_{40} \mathrm{Ni}_{10} \mathrm{Cu}_{30} \mathrm{P}_{20}$ & 1.378 & 1.386 & 1.440 \\
$\mathrm{Au}_{76.9} \mathrm{Ge}_{13.65} \mathrm{Si}_{9.45}$ & 4.486 & 4.638 & 4.841 \\
\hline
\end{tabular}

In the present case, $\Delta G\left(T_{\mathrm{g}}\right)$ has been calculated by the various theoretical expressions given by Turnbull, $\mathrm{T}$ and $\mathrm{S}$, $\mathrm{S}$ and $\mathrm{H}, \mathrm{Ji}$ and Pan, Lad et al, Hoffman, Battezzati and Garonne. Here all expressions of $\Delta G$ are based on different temperature dependence of $\Delta C_{\mathrm{p}}$. All these expressions estimate $\Delta G\left(T_{\mathrm{g}}\right)$ with minimum experimental data available. The calculated values of $\Delta G\left(T_{\mathrm{g}}\right)$ are shown in table 1. Based on the experimental data available in literature for few MGs, it is observed from the above calculated values of $\Delta G\left(T_{\mathrm{g}}\right)$ by different expressions that provide accurate values of $\Delta G$ at $T_{\mathrm{g}}$ for all systems. The experimental values of $\Delta G\left(T_{\mathrm{g}}\right)$ for $\mathrm{Mg}_{65} \mathrm{Cu}_{25} \mathrm{Y}_{10},{ }^{18} \mathrm{Zr}_{41.2} \mathrm{Ti}_{13.8} \mathrm{Cu}_{12.5} \mathrm{Ni}_{10} \mathrm{Be}_{22.5}{ }^{25}$ $\mathrm{Pd}_{40} \mathrm{Ni}_{40} \mathrm{P}_{20},{ }^{28} \mathrm{Pd}_{40} \mathrm{Ni}_{10} \mathrm{Cu}_{30} \mathrm{P}_{20}{ }^{27}$ and $\mathrm{Au}_{76.9} \mathrm{Ge}_{13.65} \mathrm{Si}_{9.45}{ }^{28}$ are as shown in table 2. For $\mathrm{Pd}_{40} \mathrm{Ni}_{40} \mathrm{P}_{20}$ the experimental results lie close to the values obtained by $\mathrm{S}$ and $\mathrm{H}$ expression, whereas for $\mathrm{Pd}_{40} \mathrm{Ni}_{10} \mathrm{Cu}_{30} \mathrm{P}_{20}$ alloy Hoffman and LadII expressions show better agreement. Also it was found that $\mathrm{T}$ and $\mathrm{S}$ as well as $\mathrm{B}$ and $\mathrm{G}$ provide good results for other BMGs. Hence, these expressions may give accurate results for few BMGs, but it may not be true for all the cases. So, one cannot predict which equation gives better results for evaluation of $\Delta G$, for a wide range of MGs with different compositions. As stated by Battezzati and Garonne ${ }^{33}$ the value $\gamma$ should be equal to 0.8 for all MGs, but from the table 1 it can be observed that it varies for different MGs. The reason for variation of $\gamma$ can be the difficulty to choose suitable crystallization step in multistep crystallization process for multicomponent MGs. Moreover $T_{x}$ and $\Delta H_{x}$ are also heating rate dependent. ${ }^{42}$ So $\gamma$ cannot be considered as constant and it is calculated by using equation (11). There are some more expressions available in literature ${ }^{43-45}$ to determine $\Delta G$, which require more experimental parameters to obtain exact values.

Also thermodynamic analysis is carried out by the expressions of $\Delta G$ given by Lele et $a l^{6}$ and Dubey and Ramchandrarao, ${ }^{36}$ which are found to be in close agreement with the experimental results. The values of $\Delta G\left(T_{\mathrm{g}}\right)$ as calculated by both expressions are shown in table 2 .

The metallic alloy is considered to be a good glass former if the value of $\Delta G$ is low. Pd-based metallic alloys are found to have highest GFA, having minimum critical cooling rate. ${ }^{46}$ Here the value of $\Delta G$ of $\mathrm{Pd}_{40} \mathrm{Ni}_{10} \mathrm{Cu}_{30} \mathrm{P}_{20}$ composition was found to be the lowest $\left(=1.378 \mathrm{~kJ} \mathrm{~mol}^{-1}\right)$ among all composition indicating its higher GFA.

\section{Conclusion}

Based on reasonably good correlation with $d_{\mathrm{c}}$, thermodynamic parameter $\Delta G$ reflects the GFA of metallic alloys. $\Delta G$ shows a negative correlation with $d_{\mathrm{c}}$, whereas other parameters show a positive correlation. The correlation of $d_{\mathrm{c}}$ with other parameters also shows linear dependence, suggesting that they are equally important to predict GFA of all MGs. $T_{\text {rg }}$ also show a high correlation with $d_{\mathrm{c}}$, hence it is a good GFA indicator. So thermodynamically the GFA of the metallic alloys can also be predicted and alloy with higher GFA can be designed. By comparing the values of GFA parameters of glass-forming alloys, one can conclude that $\mathrm{Pd}_{40} \mathrm{Ni}_{10} \mathrm{Cu}_{30} \mathrm{P}_{20}$ has high GFA among all as it has lowest value of $\Delta G$ and large stability against crystallization, indicated by greater value of $\Delta T_{x}(=85 \mathrm{~K})$.

\section{Acknowledgement}

SRP and SK are grateful to the Department of Science \& Technology (DST), Government of India, for providing financial assistance under the DST-INSPIRE and DSTPURSE fellowship scheme, respectively.

\section{References}

1. Schuh C 2007 Acta Mater. 554067

2. Ashby M F and Greer A L 2006 Scr. Mater. $\mathbf{5 4} 321$

3. Inoue A 2000 Acta Mater. 48279

4. Inoue A, Zhang T and Masumoto T 1993 J. Non-Cryst. Solids 473156

5. Turnbull D 1969 Contem. Phys. 10473

6. Lele S, Dubey K S and Ramchandrarao P 1985 Curr. Sci. 54 994

7. Thompson C V and Spaepen F 1979 Acta Metall. 271855

8. Lad K N, Pratap A and Raval K G 2002 J. Mater. Sci. Lett. 21 1419

9. Guo S, Lu Z P and Liu C T 2010 Intermetallics 18883

10. Tang C, Li Y, Pan W, Du Y, Xiong X, Zhou Q, Wang J and Zhou H 2012 J. Non-Cryst. Solids 3581368

11. Senkov O N 2007 Phys. Rev. B 76104202

12. Xiu-lin J and Ye P 2009 Trans. Nonferrous Met. Soc. China 19 1271 
13. Inoue A, Zhang T and Masumoto T 1990 Mater. Trans. JIM 31 177

14. Du X H, Huang J C, Liu C T and Lu Z B 2007 J. Appl. Phys. 101086108

15. Yuan Z Z, Bao S L, Lu Y, Zhang D P and Yao L 2008 J. Alloys Compd. 459251

16. Suo Z Y, Qiu K Q, Li Q F, You J H, Ren Y L and Hu Z Q 2010 Mater. Sci. Eng. A $\mathbf{5 2 8} 429$

17. Senkov O N, Scott J M and Miracle D B 2006 J. Alloys Compd. 424394

18. Busch R, Liu W and Johnson W L 1998 J. Appl. Phys. 834134

19. Inoue A, Kato A, Zhang T, Kim S G and Masumoto T 1991 Mater. Trans. JIM 32609

20. Men H, Hu Z Q and Xu J 2002 Scr. Mater. 46699

21. Zheng Q, Xu J and Ma E 2007 J. Appl. Phys. 102113519

22. $\mathrm{Ma} \mathrm{H}$ and Fecht H J 2008 J. Mater. Res. 232816

23. Shen J, Chen Q J, Sun J F, Fan H B and Wang G 2005 Appl. Phys. Lett. 86151907

24. Li Y, Poon S J, Shiflet G J, Xu J, Kim D H and Loffler J F 2007 MRS Bull. 32624

25. Busch R, Kim Y J and Johnson W L 1995 J. Appl. Phys. 77 4039

26. Lu I R, Willde G, Gorler G P and Willnecker R 1999 J. NonCryst. Solids 250-252 577

27. Cai A H, Xiong X, Liu Y, Chem H, An W K, Li X S, Zhou Y and Luo Y 2008 Eur. Phys. J. B 64147
28. Haruyama O, Watanabe T, Yuki K, Horiuchi M, Kato $\mathrm{H}$ and Nishiyama N 2011 Phys. Rev. B 83064201

29. Myung W N, Bae H Y, Hwamg I S, Kim H G, Nishiyama N, Inoue A and Greer A L 2001 Mater. Sci. Eng. A 304-306 687

30. Chen H S and Turnbull D 1968 J. Chem. Phys. 482560

31. Lad K N, Raval K G and Pratap A 2004 J. Non-Cryst. Solids 334-335 259

32. Hoffman J D 1958 J. Chem. Phys. 291192

33. Battezzati L and Garonne E 1984 Z. Metallk. 75305

34. Singh H B and Holz A 1983 Solid State Commun. 45985

35. Ji X L and Pan Y 2007 J. Non-Cryst. Solids 3532443

36. Dubey K S and Ramchandrarao P 1984 Acta Metall. 3291

37. Mondal K and Murty B S 2005 J. Non-Cryst. Solids 3511366

38. Weinberg M C 1994 J. Non-Cryst. Solids 16781

39. Cai A H, Xiong X, Liu Y, An W K, Tan J Y and Pan Y 2009 J. Alloys Compd. $\mathbf{4 6 8} 432$

40. Lu Z P and Liu C T 2002 Acta Metall. 503501

41. Lu Z P and Liu C T 2003 Phys. Rev. Lett. 9111

42. Dhurandhar H, Shankar Rao T L, Lad K N and Pratap A 2008 Philos. Mag. Lett. 88239

43. Jones D and Chadwick G 1971 Philos. Mag. 24995

44. Singh P K and Dubey K S 2012 Ther. Chim. Acta 530120

45. Li P, Wang G, Dong D and Shen J 2013 J. Alloys Compd. 550 221

46. Nishiyama N and Inoue A 2002 Mater. Trans. 431913 